\title{
Comparative Study of Forward Wingtip Fence and Rearward Wingtip Fence on Wing Airfoil Eppler E562
}

\author{
Setyo Hariyadi S.P. ${ }^{a}$, Sutardi ${ }^{\mathrm{b}}$, Wawan Aries Widodo ${ }^{\mathrm{b}}$, Bambang Juni Pitoyo \\ ${ }^{\mathrm{a} A v i a t i o n}$ Polytechnic of Surabaya, Indonesia \\ ${ }^{\text {b} F l u i d ~ M e c h a n i c ~ L a b o r a t o r y, ~ M e c h a n i c a l ~ E n g i n e e r i n g ~ D e p a r t m e n t, ~ F T I, ~ I T S ~}$ \\ Surabaya, Indonesia \\ e-mail: hudzaifahsetyo@gmail.com
}

\begin{abstract}
The perfect wing is a dream that many airplanes has manufactured have been striving to achieve since the beginning of the airplane design. There are some aspect that most influence in aircraft design lift, drag, thrust, and weight. The combination of these aspects leads to a decrease in fuel consumption, which reduces pollution in our atmosphere and increase in economic revenue. One way to improve aircraft performance is to modify the tip of the wing geometry, which has become a common sight on today's airplanes. With computational programs, the effects on drag due to wingtip devices can be previewed. This research was done numerically by using turbulence model k- $\omega$ SST. Reynolds number in this research was $2,34 \times 10^{4}$ with angle of attacks are $0^{\circ}, 2^{\circ}, 4^{\circ}, 6^{\circ}$, $8^{\circ}, 10^{\circ}, 12^{\circ}, 15^{\circ}, 17^{\circ}$ and $19^{\circ}$. The model specimen is wing airfoil Eppler 562 with winglets. Two types of wingtips are used: forward and rearward wingtip fence. From this study, it was found that wingtip fence reduced the strength of vorticity magnitude on the $x$ axis compared to plain wings. The leakage of fluid flow effect at the leading edge corner of the wingtip, giving pressure gradient and slightly shifting towards the trailing edge. this occurs in the plain wing and rearward wingtip fence but does not occur in the forward wingtip fence.
\end{abstract}

Keywords: airfoil; winglet; Eppler 562; lift; drag

\section{INTRODUCTION}

The winglet is one of the accessories on the wing of the plane that allows improving on-wing performance without lengthening wingspan. Winglets may be additional fins mounted on the wingtips, or may be extensions of the wings bent vertically. Winglet blocked the vortex at the tip of the wing (tip vortex) caused by the airflow jump from the lower surface to the upper surface that results in the occurrence of trailing vortex. This condition will inhibit the movement of the plane and decrease the effective extent of the wing due to increased drag force for the aircraft. The main function of the winglet to decrease the induced drag so that the aircraft can quickly fly through the sky.

The use of wingtip plays an important role in aircraft design. Particularly in the field of aerodynamics, aircraft are very concerned about the aspects that are very influential on the lift coefficient and drag coefficient of the design so that ultimately will produce optimal aerodynamic performance.

Portillo [1] uses several types of winglets on the wing with airfoil NACA 2415 at the attack angle $0^{\circ}, 4^{\circ}, 8^{\circ}, 12^{\circ}$ and $16^{\circ}$. Type of winglet used is blended, wingtip fence and circular profile. Total vorticity of minimum magnitude is found in wingtip fence and blended winglet. The intensity of the wingtips vortices is associated with lift. Wingtip fence has a minimum vorticity magnitude area but has a higher vorticity strength than a blended winglet. 
Therefore, it is proven that the winglet can reduce wingtip vorticity magnitude. If vorticity magnitude can be reduced, induced drag associated with the formation of wingtip vortices can be decreased so that drag decreases and aircraft performance can be improved. The drag coefficient increases as the angle of attack increase likewise the lift coefficient increases as the angle of attack increases. Aerodynamic performance can be seen from the $C L / C D$ ratio of the plain wing and with the winglet. The performance of the wing with wingtip fence shows an increase only at $4^{\circ}$ of attack angle. The rest on the wing without winglet shows better performance.

Turanoğuz [2] compared the use of blended winglet, hoerner wingtip and shifted downstream winglet against plain wing on wing with airfoil Eppler 562 on steady-state condition. The general result the addition of winglet will increase $C L / C D$. The resulting drag coefficient is lower than plain wing but is not visible increase in the stall point. $C L / C D$ on wing increased with addition winglet than plain wing due to its drag coefficient decrease and not because of the increase of lift coefficient.

Hariyadi [3] compared vorticity magnitude pattern of forward and rearward wingtip fence with cant angle variation $\delta=90^{\circ}$. Vorticity magnitude area behund the wing increases with the increase of the angles of attack. Forward wingtip fence succeeds in reducing "jump" of the fluid flow from the lower surface to the upper surface although the vorticity magnitude increases wider area at a high angle of attack.

Gavrilović [4] used several types of winglets in commercial aircraft use. CFD simulation was used on NACA 64412 airfoil to test the effect of winglet use on aircraft performance. From the study, it was found that the maxi winglet produces best lift to drag ratio performance than other winglets. The maximum lift to drag ratio obtained is $15 \%$. Using winglets will delay the separation and reduce total drag. However, induced drag also increases with the presence of wetted surfaces.

This research used airfoil type Eppler 562 for Unmanned Aerial Vehicle (UAV) application. Winglet with variations forward and rearward wingtip fence is studied to see the influence of the wingtip fence for increased performance wing and drag reduction that occurs with some angles of attack.

\section{METHOD}

This research was marked numerically using Ansys 19 with turbulence model k- $\omega$ SST. Freestream velocity $10 \mathrm{~m} / \mathrm{s}\left(R e=2.3 \times 10^{4}\right)$ with $\alpha=0^{\circ}, 2^{\circ}, 4^{\circ}, 6^{\circ}, 8^{\circ}, 10^{\circ}, 12^{\circ}, 15^{\circ}$, $16^{\circ}, 17^{\circ}, 19^{\circ}$ and $20^{\circ}$. Test models specimens are airfoil Eppler 562 . Winglet will be served with a variation of the forward and rearward wingtip fence. Reynolds number is chosed based on the wing chord length and freestream velocity. Model specimen form wing airfoil E562 with winglets like a wingtip fence dimension Figure 1 and Figure 2. Figure 3 is the simulation domain and the boundary conditions used in the simulation. The properties of the environment conditions refer to Hariyadi research [3].

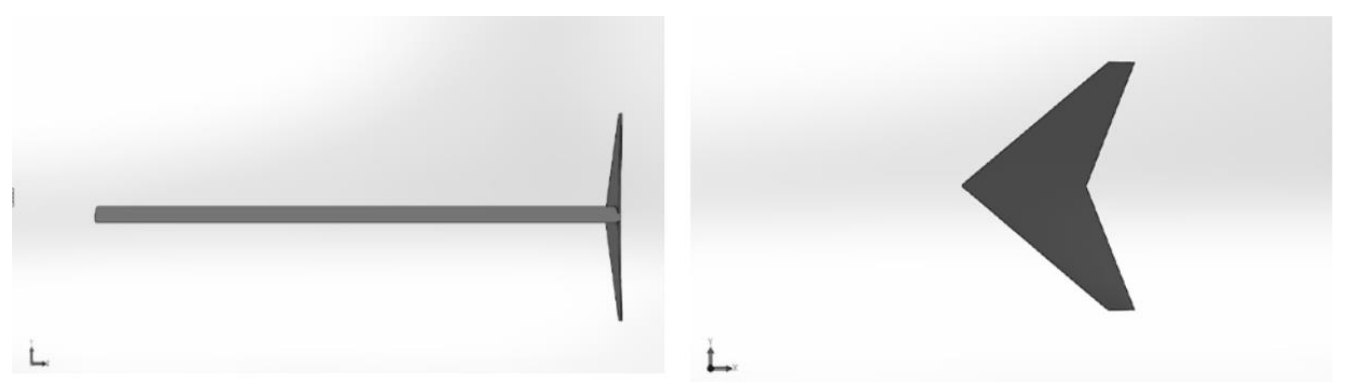

Figure 1. Forward Wingtip Fence Model [3]

In the use of simulation software requires optimum grid and meshing in postprocessing steps and pre-processing. Grid independence needed to determine the extent and structure of the grid so that the best and most efficient model results closer to the real conditions. 


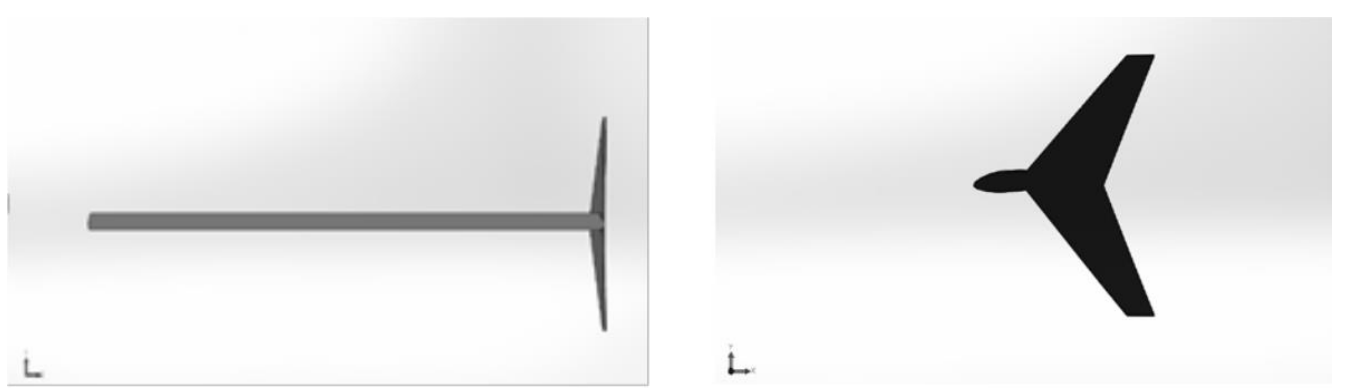

Figure 2. Rearward Wingtip Fence Model [3]

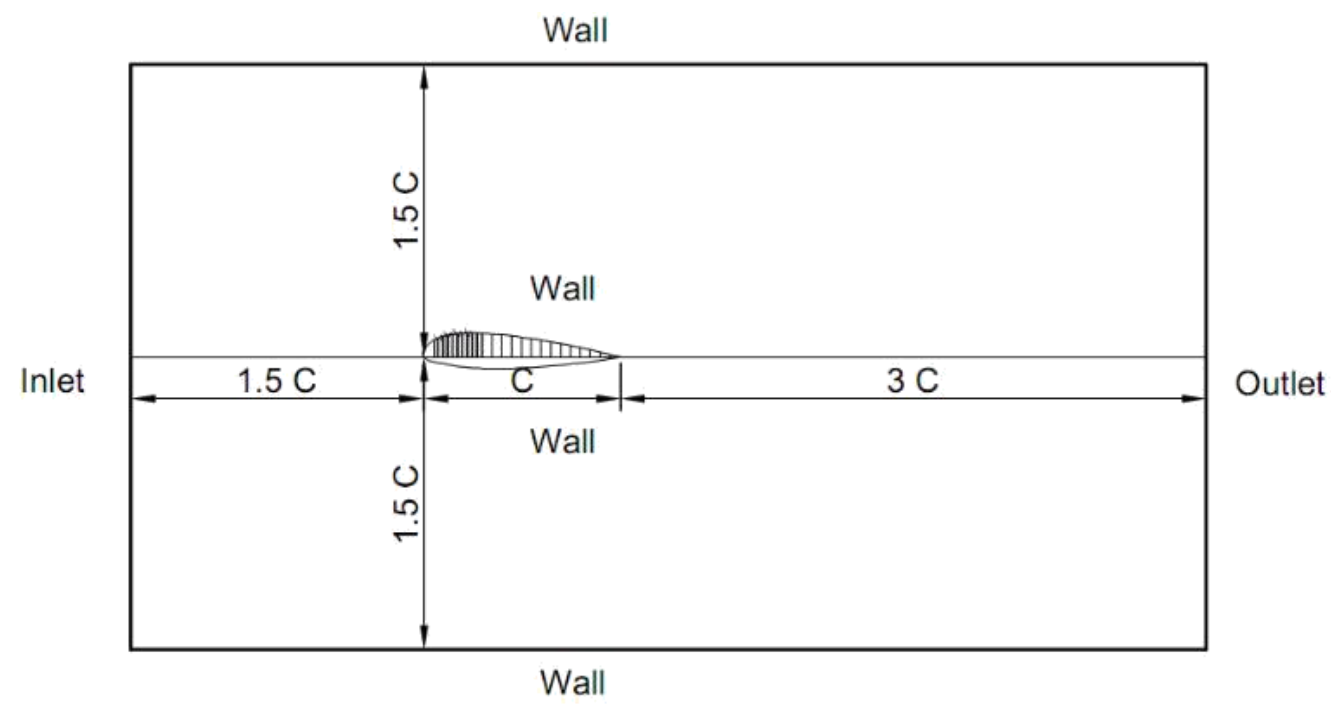

Figure 3. Modeling dimensions [5]

Grid Independence is a method for determining the optimum of experimental value. It should be understood that the use of the number of elements in numerical modeling affects the results. More elements in the simulation give more accurate results but the running time becomes longer. The optimum point is the point where the result indicates the accuracy with the minimum number of elements possible. Besides, based Kontogianis [6], the most optimal results obtained when the drag coefficient with meshing previously approximately $y^{+}$less than 5.

Grid independence uses to get the number of meshing which tends constant value to obtain an accurate result with optimum time running time. The distribution of the number of meshing into 5 types, and then the type of meshing will be compared $C D$ values of each meshing. $C D$ values of grid independence are shown in Table 1. It displays a meshing variation of the grid independence 3-D test model on Reynolds number $2.3 \times 10^{4}$.

Table 1. Grid Analysis of Independence Model E562 Three Dimensions Without Winglet [3]

\begin{tabular}{lcccc}
\hline Type Meshing & Number of Cells & Inflation Layer & CD & $\mathbf{y}^{+}$ \\
\hline Meshing A & 469.682 & 40 & 0,86 & 2,1 \\
Meshing B & 768.081 & 40 & 0,88 & 1,4 \\
Meshing C & 569.313 & 40 & 0,90 & 0,8 \\
Meshing D & 353.120 & 40 & 0,92 & 2,1 \\
Meshing E & 335.582 & 40 & 0,93 & 2,8 \\
\hline
\end{tabular}

In this research, to get the best result used Kontogianis research (2016) criterion that $y+$ is less than 1. Based on Table 1, the meshing used for the next simulation is Meshing 
C. To determine the most optimum grid by using grid independence, the chosen meshing is re-examined and compared with the Hariyadi research (2018). The velocity used in the Turanoguz research [2] was $45 \mathrm{~m} / \mathrm{s}$. The results obtained from the test are shown in Fig. 4. When viewed from graphs, the selected grid is close to Turanoguz research [2].

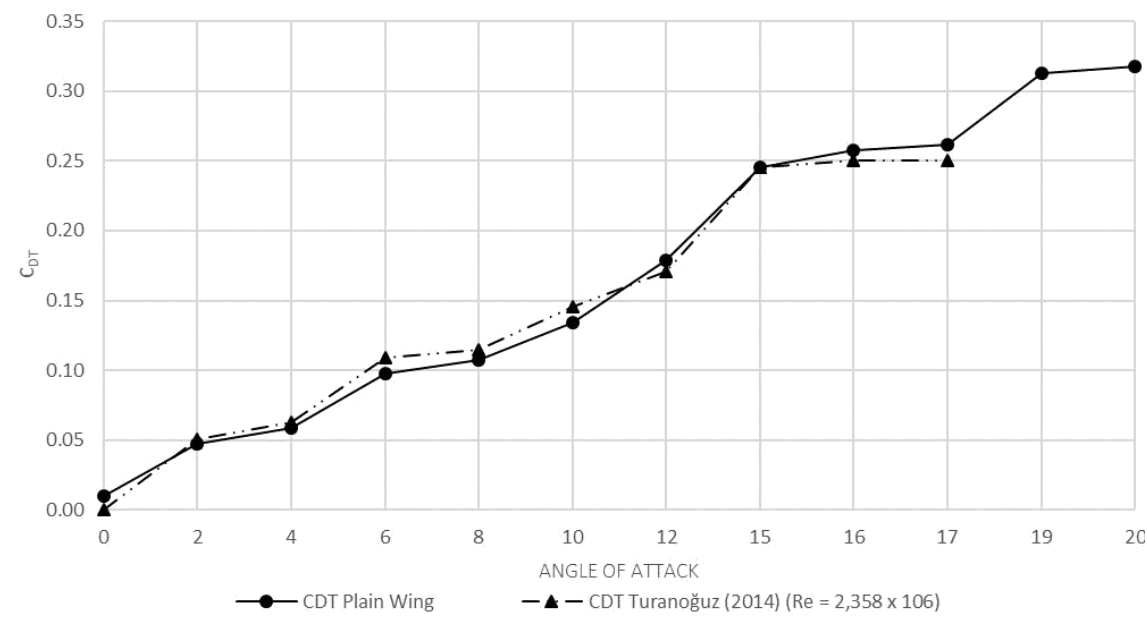

a. CDT grid independece

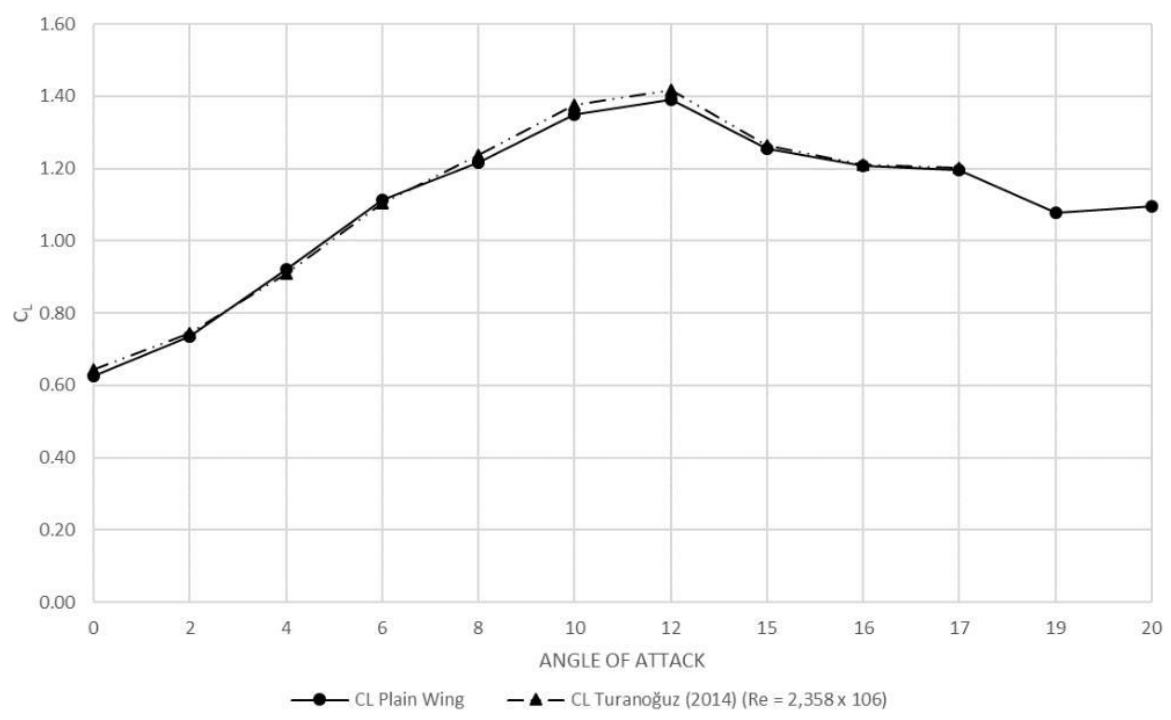

b. $C L$ grid independece

Figure 4. Comparison of CDT and CL grid independece and Turanoguz research [2]

\section{RESULTS AND Discussion \\ Pressure Contour}

Figure 1 (a) shows the visualization of pressure distribution on the upper side and lower side of plain wing E562. In general, there is an increase in the pressure gradient on the lower side and a decrease in the pressure gradient on the upper side as the angle of attack increases. The movement of the fluid from the lower side to the upper side starting from the rear of the trailing edge is shown in blue which has a lower pressure towards the upper edge which is more visible with the increase of the angle of attack. On the upper surface, the fluid flow jump shows with the color difference indicating the pressure drop in the area on the wingtips. Figure 5 (b) it is shown that the visualization of pressure 
distribution on the upper surface and lower surface of the wing with forward wingtip fence E562. Pressure contour increase on the lower surface and a decrease in the upper surface as the angle of attack increases. At the wingtip area, forward wingtip fence can prevent the occurrence of a fluid jump from the lower surface to the upper surface. The decrease in pressure that occurs on the upper side generally shows the effect of the increase of the angle of attack. Figure 5 (c) shows the visualization of pressure distribution on the upper side and lower side rearward wingtip fence E562. In general, there is an increase in the pressure gradient on the lower side and a decrease in the pressure gradient on the upper side as the angle of attack increases. At the wing tip area, forward wingtip fence can prevent the occurrence of the fluid leap from the lower side to the upper side. The decrease in pressure that occurs on the upper surface generally shows the effect of the increase of the angle of attack. On the lower surface of the wingtip, it shows a decrease in pressure up to $\alpha=17^{\circ}$. Leakage of this flow is possible because of the leading edge slightly open, causing a gap for the flow to jump from the lower surface to the upper surface. The effect of leakage of flow in the leading edge increases at $\alpha=17^{\circ}$ where the gradation of pressure color that appears at the lower side is very high while the upper side is very low compared to plain wing and forward wingtip fence.

From the phenomenon in Figure 5, it appears that there are differences in pressure, especially on the wingtip area. Low pressure on the wingtip indicates low energy in the area. With the low pressure and low energy will prevent and damage the air flow through it. The air flow through the area with low air pressure and low energy will divert the flow in an unexpected direction. This requires further discussion.

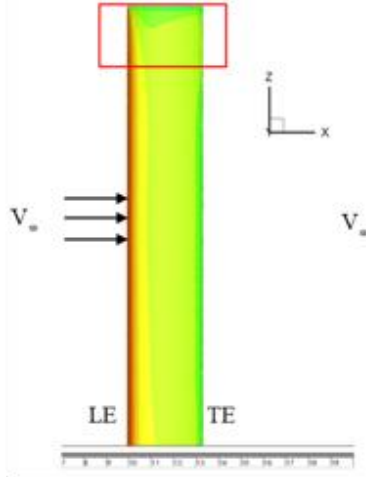

Lower Side

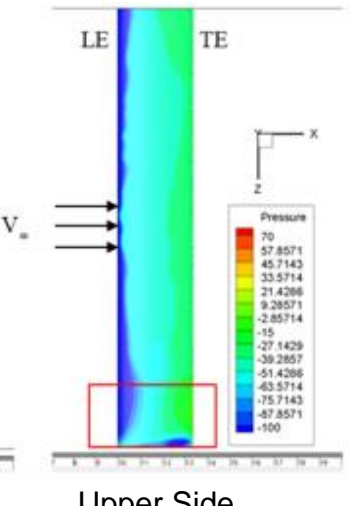

Upper Side

(a) Plain Wing $\alpha=17^{\circ}$

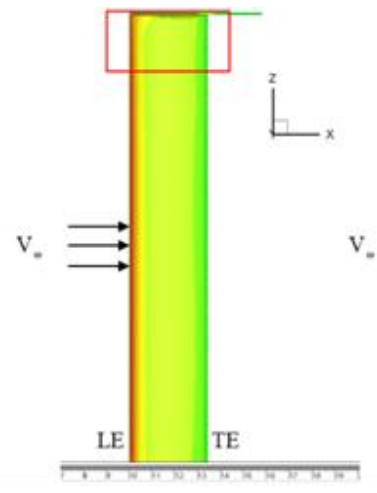

Lower Side

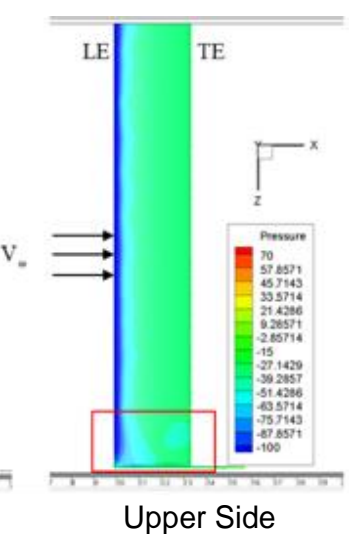

(b) Forward Wingtip Fence $\alpha=17^{\circ}$

(LE : Leading Edge, TE : Trailing Edge)
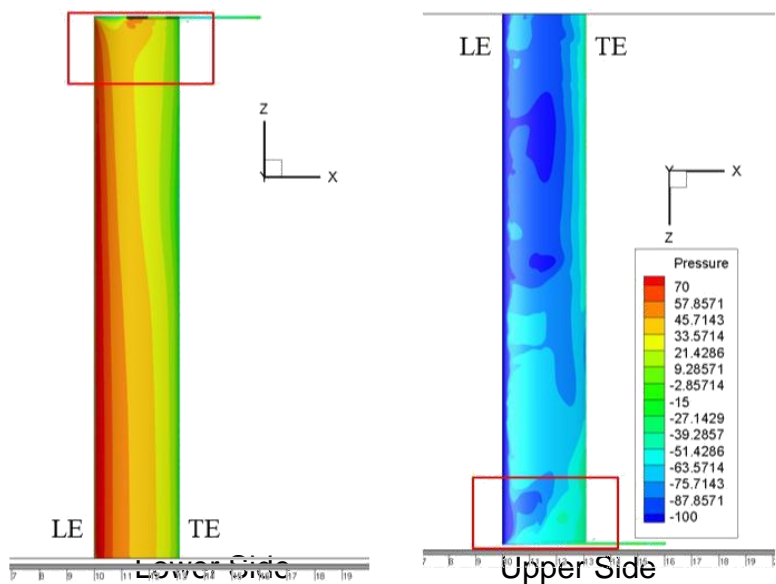

(c) Rearward Wingtip Fence $\alpha=17^{\circ}$

Figure 5. Pressure Contour (LE : Leading Edge, TE : Trailing Edge) 


\section{Turbulent Intensity Contour}

In Figure $6(a)$, it is shown that the plain wing turbulence intensity of $\alpha=16^{\circ}$ at wingtip area with high turbulence widens. This is due to the leakage of fluid flow at the tip of the leading edge of the wingtip, giving rise to a wider velocity gradient and slightly shifting towards the trailing edge. At the midspan, the leading edge experiences an increase in the intensity of the turbulence on the contrary on the trailing edge, there is a narrowing of the area of high turbulence intensity.

In Figure 6 (b) shows the turbulence intensity of the wing with forward wingtip fence at $\alpha=16^{\circ}$. It is shown that turbulence intensity decrease compared to plain wing, especially in the wingtip area. It is shown that fluid flow leakage from the lower surface to the upper surface on the wingtip can be properly retained by the forward wingtip fence. This is marked by the narrowing of the area of high turbulence intensity.

In Figure 6 (c) shows turbulence intensity of wing with rearward wingtip fence at $\alpha=$ $16^{\circ}$. In the wingtip, the area with high turbulence is slightly wider than the forward wingtip fence. This is due to the leakage of fluid flow at the tip of the leading edge of the wingtip, giving rise to a wider velocity gradient and slightly shifting towards the trailing edge. Low turbulence intensity at $\alpha=16^{\circ}$ is no longer seen because the fluid flow jump tends to be more towards the side near the rearward wingtip fence.

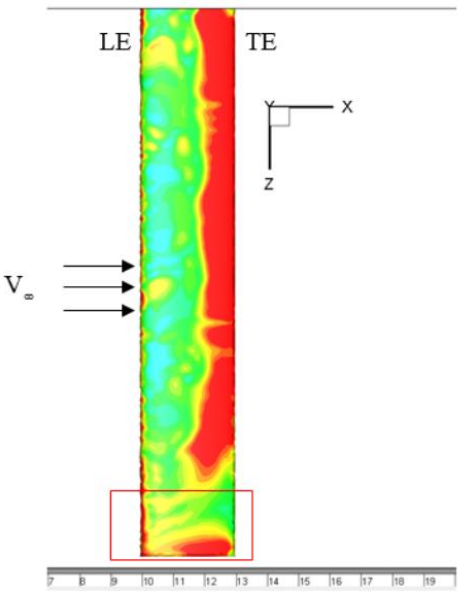

(a) Upper Side Plain Wing $\alpha=16^{\circ}$

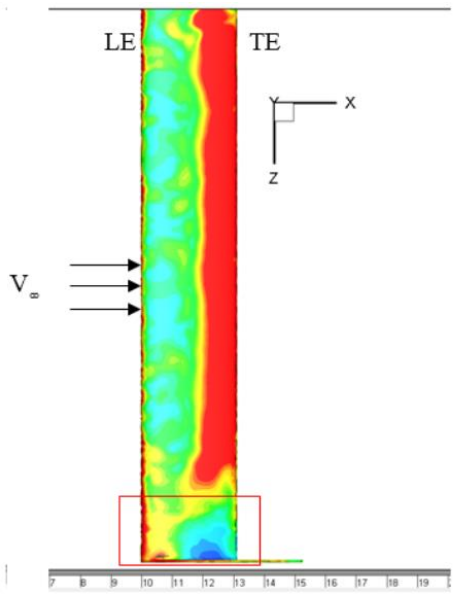

(b) Upper Side Forward Wingtip Fence $\alpha=16^{\circ}$

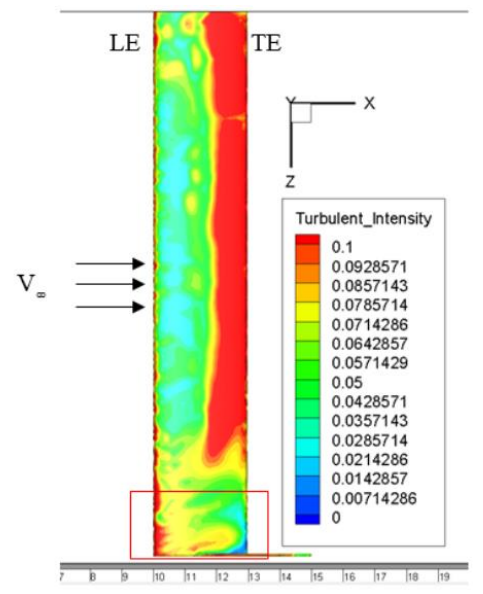

(c) Upper Side Rearward Wingtip Fence $\alpha=16^{\circ}$

Figure 6. Turbulent Intensity Contour (LE: Leading Edge, TE : Trailing Edge)

\section{Velocity Pathline}

In Figure 7 (a) and (b), it is shown that the velocity contour and the pathline of the flow passing through the Eppler 562 plain wing at $\alpha=17^{\circ}$ from the midspan and near the tip area $(z / s=0.85)$. It can be seen that the velocity contour and pathline in each variation show a different pattern. At $\alpha=17^{\circ}$, there is not much difference between the velocity passing through the midspan on the Eppler 562 plain wing and the Eppler 562 with winglet. But in the area near the tip $(z / \mathrm{s}=0.85)$, it can be seen in the Eppler 562 airfoil with winglets having greater velocity. This is due to the pressure on the surface of the Eppler 562 airfoil with winglets smaller than plain wings. This causes the Eppler 562 airfoil with a winglet to have greater velocity on its upper surface.

At $\alpha=17^{\circ}$, there is a difference in the flow phenomenon that passes through the airfoil midspan. The Eppler 562 airfoil with forward wingtip fence has smaller wake than plain wing (Figure 7 (c) and (d)). The same thing happened with rearward wingtip fence which has smaller wake than plain wing even though it is bigger than the forward wingtip fence (Figure 7 (e) and (f)). This phenomenon resulted in an increase in the drag force on the Eppler 562 airfoil plain wing.

To get more information about the shape and extent of the wake, further discussion is needed. It is necessary to explore the 3-dimensional shape of the wake shape. This will add wake information to Figure 7 which requires a depiction of the $y-z$ axis. This refers to research [7][8][9][10][11]. 

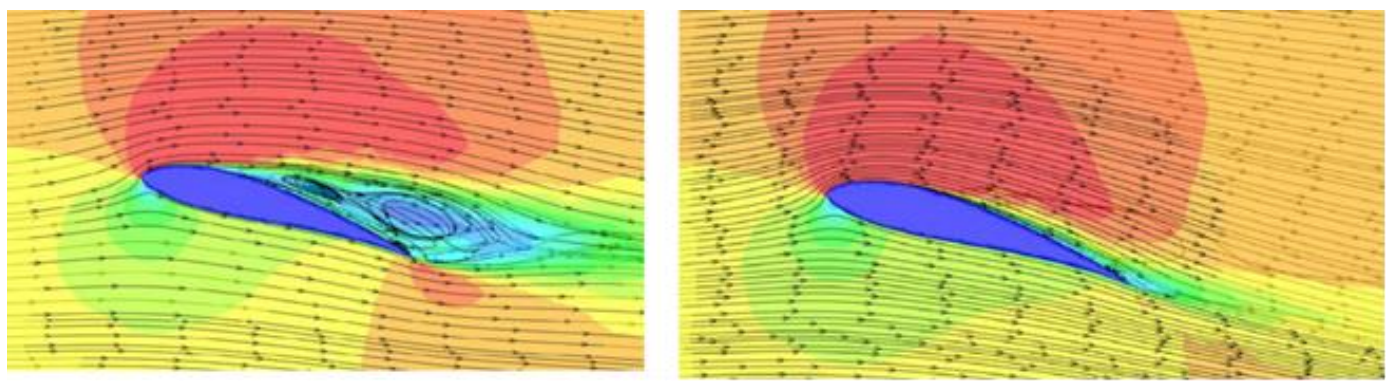

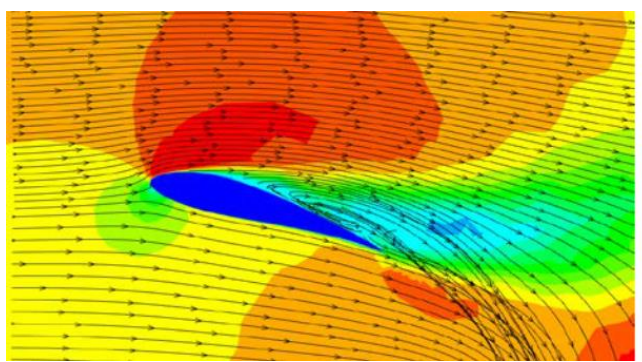

(c) Forward Wingtip Fence $\alpha=17^{0} \mathrm{z} / \mathrm{s}=0,5$

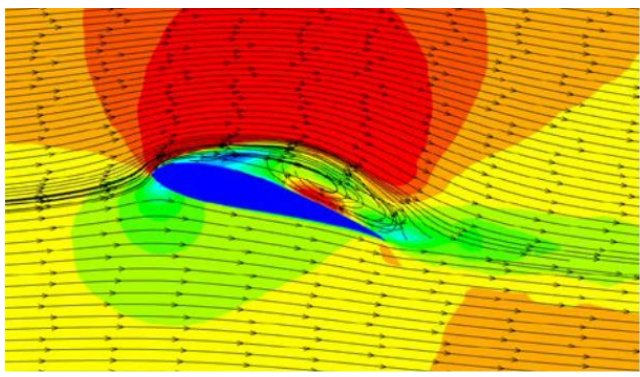

(e) Rearward Wingtip Fence $\alpha=17^{\circ} \mathrm{z} / \mathrm{s}=0,5$

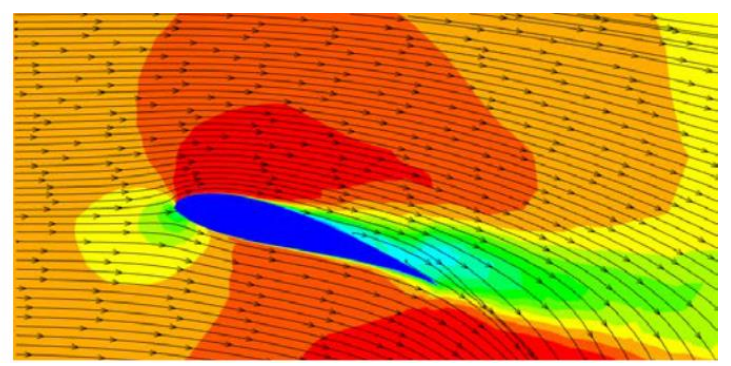

(d) Forward Wingtip Fence $\alpha=17^{\circ} \mathrm{z} / \mathrm{s}=0,85$

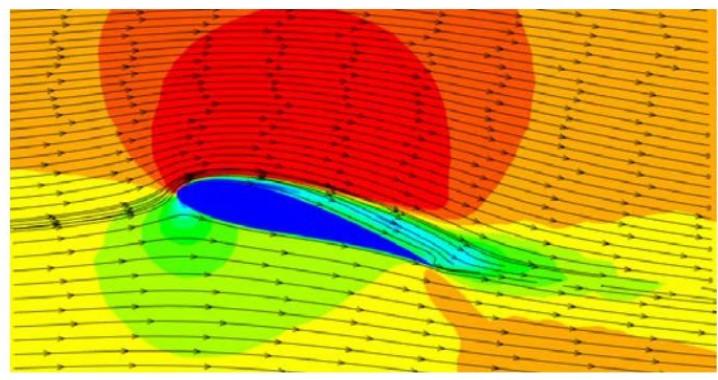

(f) Rearward Wingtip Fence $\alpha=17^{\circ} z / s=0,85$

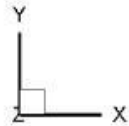

Figure 7. Velocity contour and velocity pathline on the midspan and the area near the wing tip Eppler 562

\section{CONCLUSION}

The results of this study show that use winglet can improve the performance of the wing even with the addition of winglets will increase the drag with increasing angle of attack. The winglet can improve the performance of the wing compare to the plain wing. Nevertheless, the addition of the winglets increases the total drag than plain wing especially as the angle of attack increase. From a numerical study found that use winglet can produce the result:

1. In the wingtip region, rearward wingtip fence is less able to prevent the occurrence of fluid jumps from the lower side to the upper side than forward wingtip fence. The decrease in pressure contour that occurs on the upper surface generally shows the effect of the increase of the angle of attack.

2. The leakage of fluid flow effect at the leading edge corner of the wingtip, giving rise to a wider pressure gradient and slightly shifting towards the trailing edge. this occurs in the plain wing and rearward wingtip fence but does not occur in the forward wingtip fence.

3. In the midspan section, the addition of a winglet produces a wake that is smaller than the plain wing. This contributes to the decrease in induced drag on Eppler 562 with the addition of winglets. In the behind wingtip area, the wake has smaller than in the midspan section. 


\section{REFERENCES}

1. A. C. Portillo, "CFD Analysis of Winglets" B. Eng (Hons) Aeronautical \& Mechanical Engineering, 2011.

2. E. Turanoguz and N. Alemdaroglu, "Design of a medium range tactical UAV and improvement of its performance by using winglets," 2015 Int. Conf. Unmanned Aircr. Syst. ICUAS 2015; 2015: 1074-1083. 10.1109/ICUAS.2015.7152399

3. S. P. Setyo Hariyadi, Sutardi, W. A. Widodo, and M. A. Mustaghfirin, "Aerodynamics analisys of the wingtip fence effect on UAV wing," Int. Rev. Mech. Eng., 2018; Vol. 12(10):837-846. https://doi.org/10.15866/ireme.v12i10.15517

4. N. N. Gavrilović, B. P. Rašuo, G. S. Dulikravich, and V. B. Parezanović, "Commercial aircraft performance improvement using winglets," FME Trans., 2015; Vol. 43(1):1-8. doi: $10.5937 / \mathrm{fmet} 1501001 \mathrm{~g}$

5. N. Mulvany, L. Chen, J. Tu, and B. Anderson, "Steady-State Evaluation of TwoEquation RANS (Reynolds-Averaged Navier-Stokes) Turbulence Models for HighReynolds Number Hydrodynamic Flow Simulations," Dep. Defence, Aust. Gov., pp. $1-54,2004$.

6. S. G. Kontogiannis, D. E. Mazarakos, and V. Kostopoulos, "ATLAS IV wing aerodynamic design: From conceptual approach to detailed optimization," Aerosp. Sci. Technol., 2016; Vol. 56:135-147. https://doi.org/10.1016/..ast.2016.07.002

7. G. Narayan and B. John, "Effect of winglets induced tip vortex structure on the performance of subsonic wings," Aerosp. Sci. Technol., 2016; Vol. 58:328-340, 2016. https://doi.org/10.1016/..ast.2016.08.031

8. S. P. Setyo Hariyadi, Sutardi, and W. A. Widodo, "Numerical study of aerodynamic analysis on wing airfoil NACA 43018 with the addition of forward and rearward wingtip fence," AIP Conf. Proc., 2016; Vol. 1778(1). https://doi.org/10.1063/1.4965745

9. H. Demir, M. Özden, M. S. Genç, and M. Çağdaş, "Numerical investigation of flow on NACA4412 aerofoil with different aspect ratios," EPJ Web Conf., 2016; Vol. 114:1-5. https://doi.org/10.1051/epiconf/201611402016

10. M. S. Genç, M. Özden, H. H. Açikel, H. Demir, and I. Isabekov, "Unsteady flow over flexible wings at different low Reynolds numbers," EPJ Web Conf., 2016; Vol. 114:16. https://doi.org/10.1051/epiconf/201611402030

11. M. S. Genç, G. Özkan, H. H. Açikel, M. S. Kiriş, and R. Yildiz, "Effect of tip vortices on flow over NACA4412 aerofoil with different aspect ratios," EPJ Web Conf., 2016; Vol. 114:2-5. https://doi.org/10.1051/epjconf/201611402027 